In carrying out a moro serious test of the hypo. thesis, we have recently, among other things, examined by $X$-rays the effect of removing progressively the xylan (initially 19.8 per cent) of celluloso fibres from manilla hemp, using an apparatus specially desigmed for taking strictly comparable photographs on one and the same film ${ }^{2}$. By this means very accurate comparisons were possible, but again no really fundamental change was revcaled. Briefly, it may be said that removing xylan from fibres of high xylan content merely makos their X-ray photographs more like those of fibres of low xylan content! Tho point of this apparently pointless verdict is that the $\mathrm{X}$-ray photographs of fibres of low xylan content ramie and Italian hemp, for example-show certain diffraction features typical of a more perfect state of crystallisation. The result of these experiments is therefore definitely in favour of the viow that tho incorporation of xylan is a sort of mixed crystallisation.

A number of common fibres were also purified by removal of lignin and encrusting hemicellulosos. As would bo expected, the effect of this treatment was in general to clarify the $\mathrm{X}$-ray photograph, and in most cases to lead to improved definition through a sharpening of the crystallite orientation. Otherwise, nothing of any great significance was observed. Much depends on the care with which the chemical pre-treatment is carried out, for it is possible to injure the crystallite orientation instead of improving it. Miles Thomas and Hewitt ${ }^{3}$ report a diminished intensity in photographs of purified fibres; but we have not observed such an effect.

The photographs and experimental deteils of the work will be published in due course. In the meantime attempts are being mado to obtain an $X$-ray pattern from xylan alone.

Textile Physics Laboratory, R. D. Prestor. University of Leods.

Biochomistry Section,

A. G. Norman.

Rothamsted Experimental Station. Aug. 16.

${ }^{1}$ Norman, Science Progress, Z7, 299 ; 1833 Cf. Astbury and Woods, Phil. Trans. Foy. Soc., A, 282, 333; 1938.
NATUR, 136, 69, July 13, 1935.

\section{Sub-Boundaries in a Crystal Grown by the Bridgman Method}

InTEREsT in irregularities observable in single erystals has arisen through the large discrepancies between the results of experimental studies of some of the physical properties of crystals and theoretical studies based on the idea of a single uniform lattice extonding throughout each single erystal.

An observable irregularity has been found in working with a single crystal of copper grown by the Bridgman method. In trying to get an undistorted section parallel to the 311 planes for use as an $\mathrm{X}$-ray polariser $^{t}$ many surfaces had to be cut, etched and examined under the microscopo. The appearance of one such section, shown in the photomicrograph (Fig. 1), suggests that tho crystal had broken down into a Iarge number of small ones, the outlines of which are seen as tho curved lines. The etching had been done with nitric acid, which develops the cube planes, so that the whole surface was covered by tiny cubes each having one corner projecting.

It was noticed that, as nearly as could be judged by eye, not only were the whole of the cubes similarly orientated, as would be expected in a single crystal, but also some of the individual cubes actually crossed tho curved boundary lines, Both effects were easily seen distributed over the whole $7 \mathrm{~mm}$. of crystal and thoy are detectable in the photomicro. graph. The arrow is parallel to a cube face. The grinding marks arc parallel to the two edges of the page. X-ray photographs showed that if the crystal had broken up into smaller ones, their oricntation was unchanged within the limits of the experimental accuracy.

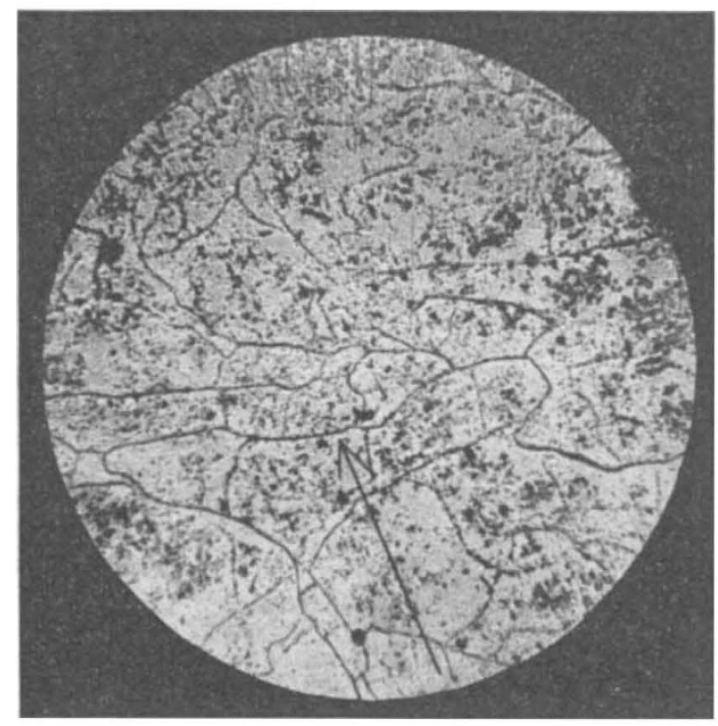

Fia. 1. Etched section of a single crystal copper fod cut parallel to (31i) planes showing, to left of arrow, sub-boundaries crossed by cube edges. ( $x 30$.

Sir Harold Carpenter kindly pointed out that the markings are similar to the 'sub-boundary' or 'veined' structures observed in many metals. In the literature, these have been studied in the individual grains (crystals) of polycrystallino material but their nature is apparently not understood yet. Smithells and Rooksby ${ }^{2}$ suggest that the sub-boundaries are formed under the influence of stresses set up during the rapid cooling of the metal (tungsten). Such a hypothesis would be untenable for copper as the observations here reported wero made upon a crystal cooled very slowly. Furthermore, Northeott ${ }^{2}$ was ablo to suppress veining in polyerystalline copper by quenching from $1,000^{\circ} \mathrm{C}$. The etching which is favourable for revealing sub-boundaries is not always favourable for showing the crystal orientation. In preparing the specimen illustrated, the acid was applied to tho clean dry surface held by the side of a running tap, so that the action could be stopped quiokly after about one second.

Since these sub-boundaries can bo found in single crystals, it is evident that their possible influence upon some physical properties can be studied in types of experiment not possible with polycrystalline material where they have been observed hitherto.

The University, W. H. GroraE Shefficld. (Royai Society Sorby Aug. 1. Research Fellow).

1 Gcorge, N $\triangle T$ TUE, 138, 180, Aug. 3, 1935

\& Smitheils and Rooks, NiTuRE, 120, 226; 1927

S Northeott, J. Iron and 'Steel Inst.. 126, 274; 1932. 